\title{
Phenoxazine derivatives induce caspase-independent cell death in human glioblastoma cell lines, A-172 and U-251 MG
}

\author{
KEN SHIRATO $^{1}$, KAZUHIKO IMAIZUMI $^{1}$, AKIHISA ABE $^{2}$ and AKIO TOMODA ${ }^{2}$ \\ ${ }^{1}$ Laboratory of Physiological Sciences, Faculty of Human Sciences, Waseda University, 2-579-15 Mikajima, \\ Tokorozawa, Saitama 359-1192; ${ }^{2}$ Department of Biochemistry, Tokyo Medical University, \\ 6-1-1 Shinjuku, Shinjuku, Tokyo 160-8402, Japan
}

Received July 25, 2006; Accepted September 26, 2006

\begin{abstract}
The apoptotic effects of 2-amino-4,4 $\alpha$-dihydro- $4 \alpha$, 7-dimethyl-3H-phenoxazine-3-one (Phx-1) and 2-aminophenoxazine-3-one (Phx-3) on human glioblastoma cell lines, A-172 and U-251 MG were studied. These phenoxazines extensively decreased the viability of A-172 and U-251 MG cells $\left(\mathrm{IC}_{50}\right.$ of Phx-1: $60 \mu \mathrm{M}$, in both lines; $\mathrm{IC}_{50}$ of Phx-3: 10 and $3 \mu \mathrm{M}$, for A-172 and $\mathrm{U}-251$ cells, respectively). Phx-1 and Phx-3 increased the population of annexin $\mathrm{V}$ and PI double-positive cells in A-172 and U-251 MG cells, resulting in cell death at late stage apoptosis/necrosis. The activities of caspase-3/7 were greatly increased in A-172 and U-251 MG cells treated with $\mathrm{Phx}-1$ or $\mathrm{Phx}-3$. However, a pan-caspase inhibitor, z-VAD-fmk, failed to reverse the antiproliferative and apoptotic effects of Phx-1 and Phx-3 in both cell lines. In conclusion, $\mathrm{Phx}-1$ and $\mathrm{Phx}-3$ exert significant anti-cancer effects against human glioblastoma cell lines, A-172 and U$251 \mathrm{MG}$, mediated by the caspase-independent apoptotic cell death pathway.
\end{abstract}

\section{Introduction}

It has been considered that drugs causing apoptotic cell death of cancer cells are ideal as the anticancer drugs, possibly because of low adverse effects $(1,2)$. In addition, the activation of the caspase family proteases and related signal pathways have been shown to be involved in the apoptosis of cancer cells treated with various chemotherapeutic agents $(3,4)$. Caspase-independent cell death mechanisms have recently been described (5-8). In particular, the caspase-independent pathway associated with apoptosis inducing factor (AIF), a mitochondrial flavoprotein that is released from the

Correspondence to: Dr Akio Tomoda, Department of Biochemistry and Research Institute of Immunological Treatment, Tokyo Medical University, 6-1-30 Shinjuku, Tokyo 160-0020, Japan

E-mail: tomoda@tokyo-med.ac.jp

Key words: 2-amino-4,4 $\alpha$-dihydro-4 $\alpha, 7$-dimethyl-3H-phenoxazine3-one, 2-aminophenoxazine-3-one, glioblastoma, apoptosis, caspase intermembrane space, and translocates to the nucleus once liberated, and BNIP3, which causes cytochrome c release and nuclear translocation of AIF, is shown to operate in the induction of apoptosis $(2,5,8)$. Park et al reported that caspase-independent cell death was caused by allicin, the major component of garlic (9). Therefore, it is of interest to study which pathway, the caspase-dependent or the caspaseindependent pathway, is involved in the cellular apoptosis of cancer cells treated with anticancer drugs.

On the other hand, phenoxazine derivatives, 2-amino4,4 $\alpha$-dihydro-4 $\alpha, 7$-dimethyl-3H-phenoxazine-3-one (Phx-1) and 2-aminophenoxazine-3-one (Phx-3), which are produced by the reaction of $o$-aminophenol and its derivative with bovine hemoglobin $(10,11)$, have been shown to exert anticancer effects on a variety of carcinoma cells such as human leukemia cell lines (12), human lung carcinoma cell lines (13), Burkitt lymphoblastoma cell lines (14), human malignant melanoma cell line (15) and pancreatic cancer cell lines (16) in vitro and in vivo. $\mathrm{Phx}-1$ and $\mathrm{Phx}-3$ cause the apoptosis of these carcinoma cell lines (12-16). However, the detailed pathways for the apoptosis caused by $\mathrm{Phx}-1$ and $\mathrm{Phx}-3$ in various carcinoma cells have not been clarified.

In the present study, we investigated the anticancer effects of Phx-1 and Phx-3 on the human glioblastoma cell lines, A-172 and U-251 MG, focusing on caspase-dependent or caspase-independent apoptotic cell death in glioblastoma cell lines that are extremely resistant to chemotherapeutic drugs.

\section{Materials and methods}

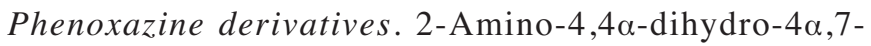
dimethyl-3H-phenoxazine-3-one (Phx-1) and 2-aminophenoxazine-3-one $(\mathrm{Phx}-3)$ were prepared according to the methods described by Tomoda et al (10) and Shimizu et al (11). The chemical structure of these compounds is illustrated in Fig. 1. Phx-1 and Phx-3 were dissolved in the mixture of dimethylsulfoxide (DMSO) and ethyl alcohol (EtOH) (3:1) to make a $20 \mathrm{mM}$ solution, and then these solutions were added to culture medium to reach final concentrations of 5-100 $\mu \mathrm{M}$ during experiments.

Cell lines and culture condition. The human glioblastoma cell lines, A-172 and U-251 MG, were obtained from the Health Science Research Resources Bank (HSRRB, Osaka, Japan). 
(A)<smiles>Cc1ccc2c(c1)OC1(C)CC(=O)C(N)=CC1=N2</smiles>

(B)

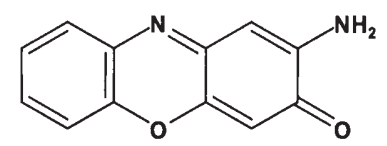

Figure 1. Chemical structure of the phenoxazine derivatives used in the present study. (A), 2-amino-4,4 $\alpha$-dihydro-4 $\alpha$,7-dimethyl-3H-phenoxazine3-one (Phx-1). (B), 2-aminophenoxazine-3-one (Phx-3).

Cells were cultured in Dulbecco's modified Eagle's medium (Kohjin Bio, Saitama, Japan) supplemented with $80 \mathrm{mg} / \mathrm{l}$ kanamycin sulfate (Wako Pure Chemicals, Tokyo, Japan) and $10 \%$ heat inactivated fetal bovine serum (FBS) (Sigma, St Louis, MO, USA) in a humidified incubator containing 5\% $\mathrm{CO}_{2} / 95 \%$ air at $37^{\circ} \mathrm{C}$.

Cell viability assay. The viability of cells was assessed fluorometrically using the CellTiter-Blue ${ }^{\mathrm{TM}}$ Cell Viability Assay (Promega, Madison, WI, USA). A-172 and U-251 MG cells $\left(8 \times 10^{4}\right.$ cells $\left./ \mathrm{ml}\right)$ were pre-cultured in Nunclon 48 -well flatbottomed microtiter plates for $24 \mathrm{~h}$, and then the cells were treated with fresh medium containing various concentrations of Phx-1 or Phx-3. After 24, 48 and 72 h, the culture medium was discarded, and the cells were treated with fresh medium containing the CellTiter-Blue reagent (resazurin, 7-hydroxy3H-phenoxazine-3-one 10-oxide). The incubation was continued for $1 \mathrm{~h}$, resorufin (7-hydroxy-3H-phenoxazine-3one), the reduced form of resazurin, was analyzed using a multi-detection microplate reader (Powerscan HT, Dainippon Pharmaceutical, Osaka, Japan) at a wavelength of $560 \mathrm{~nm}$ excitation/590 nm emission. The viability of cells was determined by referring to the fluorescence of cells treated without Phx-1 or Phx-3.

Apoptosis and necrosis detection. The detection of apoptosis and necrosis was performed flow cytometrically using the Annexin V-FITC Apoptosis Detection Kit (Medical and Biological Laboratories, Nagoya, Japan). A-172 and U-251 MG cells $\left(8 \times 10^{4}\right.$ cells $\left./ \mathrm{ml}\right)$ treated with the indicated concentrations of Phx-1 or Phx-3, or vehicle (DMSO/EtOH) for 24,48 and $72 \mathrm{~h}$ were collected, once washed with phosphate-buffered serine (PBS, pH 7.4) and resuspended in $500 \mu 1$ of the binding buffer, into which $5 \mu 1$ of fluorescein isothiocyanate (FITC)labeled annexin V (Annexin V-FITC) and propidium iodide (PI) were added. These samples were incubated at room temperature for $5 \mathrm{~min}$ in the dark, and then analyzed with a flow-cytometer (Partec PAS, Partec, Münster, Germany). Annexin V-FITC binding and PI staining were monitored using FITC signal detector (FL1, $520 \mathrm{~nm}$ ) and phycoerythrin emission signal detector (FL3, 590-650 nm), respectively.

Cell cycle analysis. The cell cycle analysis was performed flow cytometrically using the CyStain DNA 2 step (Partec). A-172 and U-251 MG cells $\left(8 \times 10^{4}\right.$ cells $\left./ \mathrm{ml}\right)$ treated with the indicated concentrations of Phx-1 or Phx-3, or vehicle for 24, 48 and $72 \mathrm{~h}$ were once washed with PBS (pH 7.4) and treated with $1 \mathrm{ml}$ of the nuclear extraction buffer, then incubated at room temperature for $10 \mathrm{~min}$. The extracted nuclei were stained with the 4'-6-diamidino-2-phenylindole (DAPI) staining and incubated at room temperature for $10 \mathrm{~min}$ in the dark. These samples were analyzed with a flow cytometer (Partec PAS, Partec) using the cell cycle analysis program, MultiCycle AV (Phoenix Flow System, San Diego, CA, USA).

Measurement of caspase family activities. The activity of caspase-3/7, caspase- 9 and caspase- 8 was measured luminometrically using Caspase-Glo ${ }^{\mathrm{TM}} 3 / 7,9$ and 8 Assay (Promega), respectively. A-172 and U-251 MG cells were pre-cultured in Nunclon white-walled 96-well flat-bottomed microtiter plates at $5 \times 10^{3}$ cells/well for $24 \mathrm{~h}$, and then the cells were treated with fresh medium containing the indicated concentrations of Phx-1 or Phx-3, or vehicle. After 24, 48 and 72 h, the cells were treated with fresh medium, and the Caspase-Glo 3/7, 9 or 8 reagents were added into each well. After incubation was continued at room temperature for $30 \mathrm{~min}$, luminescent signals were detected using a multi-detection microplate reader (Powerscan HT, Dainippon Pharmaceutical). Under the same experimental condition, the viability of cells was concurrently assessed as described above. The activity of caspase-3/7, - 9 and -8 was corrected on the basis of the number of viable cells, and presented as the relative ratio of the activity in cells treated with $\mathrm{Phx}-1$ or Phx-3 to that in control cells treated with vehicle at each time point.

Examination by a caspase inhibitor. A-172 and U-251 MG cells were divided into three groups as follows: i) control cells treated with vehicle, ii) cells treated with the indicated concentrations of Phx-1 or Phx-3, and iii) cells co-treated with the indicated concentrations of Phx- 1 or Phx- 3 and $100 \mu \mathrm{M} N$-benzyloxycarbonyl-Val-Ala-Asp-fluoromethylketone (z-VADfmk) (Kamiya Biochemical, Seattle, WA, USA), a pan-caspase inhibitor, which was dissolved in DMSO to obtain a 20-mM solution before use. The third group of cells and another group cells were pre-treated with $100 \mu \mathrm{M}$ z-VAD-fmk and the same quantity of DMSO for $2 \mathrm{~h}$, respectively, and then treated with the indicated concentrations of $\mathrm{Phx}-1$ or $\mathrm{Phx}-3$, or vehicle, and $100 \mu \mathrm{M} \mathrm{z}$-VAD-fmk or DMSO for $48 \mathrm{~h}$. The activity of caspase-3/7 and the viability of cells were examined, and the detection of apoptosis and necrosis were performed as described above.

Statistical analysis. Experimental data were presented as means \pm SE. Unpaired Student's t-test was performed to examine the differences between each experimental group of cells. A p-value $<0.5$ was considered to indicate a statistically significant difference.

\section{Results}

Effects of Phx-1 and Phx-3 on the viability of human glioblastoma cell lines, $A-172$ and $U-251 M$. The effects of various concentrations of Phx-1 and Phx-3 on the viability of human glioblastoma cell lines, A-172 and U-251 MG, after 24, 48 and $72 \mathrm{~h}$ of treatment were investigated. Phx-1 significantly decreased the viability of A-172 (left column, Fig. 2A) and 
(A)
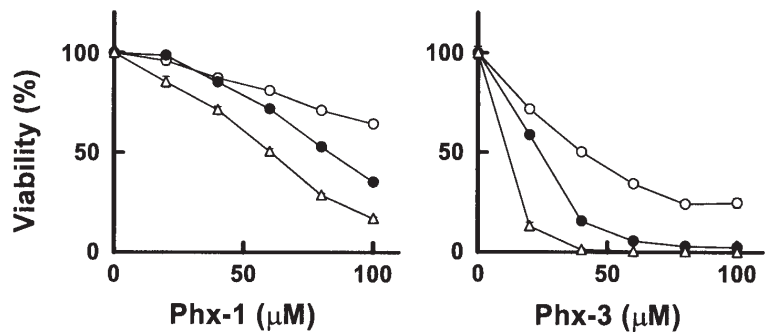

(B)
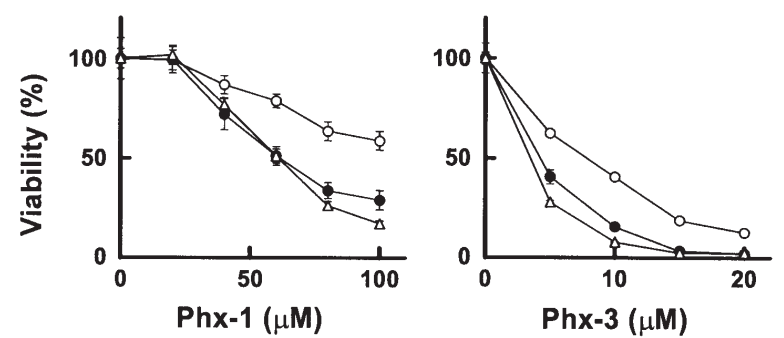

Figure 2. Effects of Phx-1 and Phx-3 on the viability of human glioblastoma cell lines, A-172 and U-251 MG. A-172 cells and U-251 MG cells were treated with vehicle alone (control) or with various concentrations of $\mathrm{Phx}-1$ (20-100 $\mu \mathrm{M})$ or Phx-3 (4-100 $\mu \mathrm{M})$, and were incubated for $72 \mathrm{~h}$. (०) $24 \mathrm{~h}$; (•) $48 \mathrm{~h} ;(\triangle) 72 \mathrm{~h}$. Values, means $\pm \mathrm{SE}(\mathrm{n}=6)$.

U-251 MG cells (left column, Fig. 2B) in a dose- and timedependent manner. The concentration to cause $50 \%$ inhibition $\left(\mathrm{IC}_{50}\right)$ of Phx-1 in these cells was $\sim 60 \mu \mathrm{M}$ in both cell lines after $72 \mathrm{~h}$ in treatment. Phx-3 exerted more drastic inhibitory effects in these cells than Phx-1 (right columns, Fig. 2). In particular, Phx-3 fully suppressed the viability of U-251 MG cells at a concentration of $15 \mu \mathrm{M}$ after $48 \mathrm{~h}$ of treatment (right column, Fig. 2B). The $\mathrm{IC}_{50}$ of Phx-3 in A-172 and U$251 \mathrm{MG}$ cells was $\sim 10$ and $3 \mu \mathrm{M}$, respectively, after $72 \mathrm{~h}$ of treatment. In summary, both phenoxazine derivatives exerted significant antiproliferative effects in the human glioblastoma cell lines, A-172 and U-251 MG, and the antiproliferative effects of Phx-3 in these cell lines were considerably stronger than those of Phx-1.

Effects of Phx-1 and Phx-3 on apoptosis/necrosis and cell cycle in A-172 and U-251 MG cells. Whether the antiproliferative effects of Phx-1 and Phx-3 in A-172 and U-251 MG cells were mediated by the induction of cell death such as apoptosis and necrosis and/or the induction of cell cycle arrest was investigated. As shown in the left columns of Fig. 3 (control), the population of cells negative for both annexin V-FITC and PI (viable cells, plots in the bottom left quadrant) was mostly observed in the control cells treated with vehicle in both A-172 and U-251 MG cells for 24-72 h. When A172 cells were treated with $80 \mu \mathrm{M}$ Phx- 1 or $30 \mu \mathrm{M} \mathrm{Phx}-3$ for 24-72 $\mathrm{h}$ (middle and right columns, Fig. 3A), the population of the viable cells gradually decreased, and that of the late phase apoptotic/necrotic cells expressed as positive for both annexin V-FITC and PI (plots in the top right quadrant) was increased in a time-dependent manner. Similar effects were observed in U-251 MG cells treated with $80 \mu \mathrm{M} \mathrm{Phx}-1$ or $10 \mu \mathrm{M}$ Phx-3 (middle and right columns, Fig. 3B), but were weaker than in A-172 cells. These results indicate that Phx-1 and Phx-3 are capable of inducing mixed types of cell death

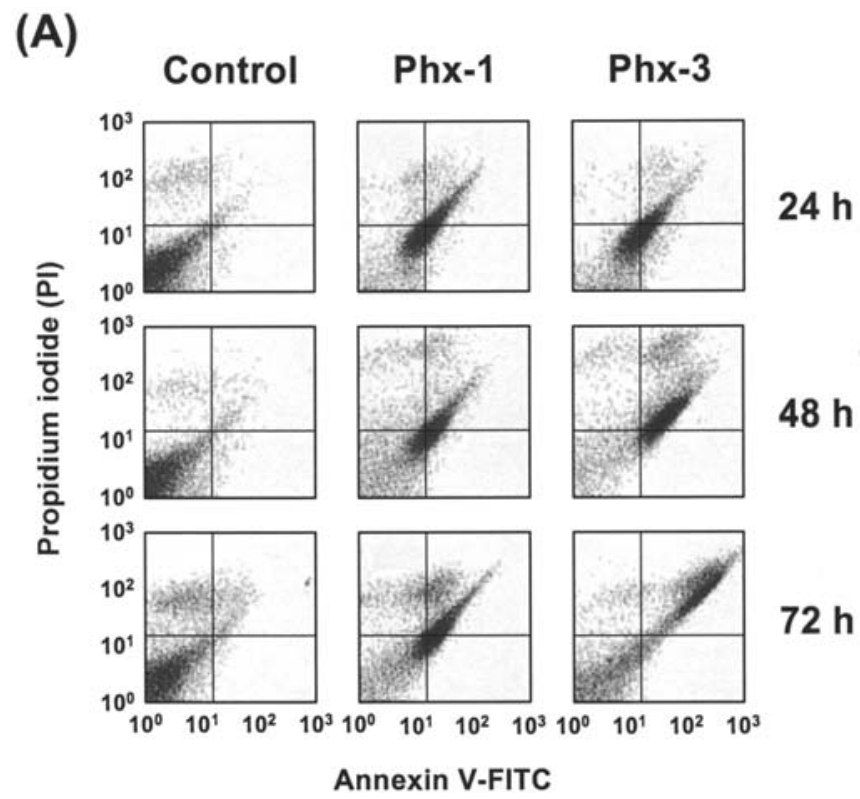

(B)

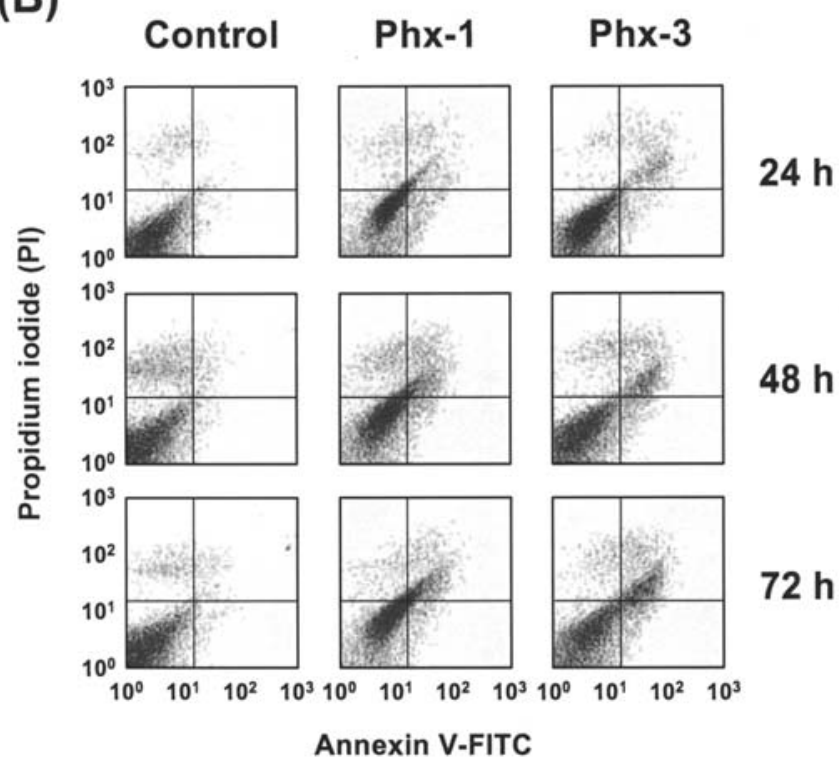

Figure 3. Analysis of the population of the viable, early-phase apoptotic, late-phase apoptotic/necrotic and necrotic cells in A-172 and U-251 MG cells treated with vehicle alone or with $\mathrm{Phx}-1$ or $\mathrm{Phx}-3$, detected by the annexin V-FITC and PI staining. A-172 cells were treated with or without $80 \mu \mathrm{M}$ Phx-1 or $30 \mu \mathrm{M}$ Phx-3, and U-251 MG cells were treated with $80 \mu \mathrm{M}$ Phx-1 or $10 \mu \mathrm{M} \mathrm{Phx}-3$ for 24,48 and $72 \mathrm{~h}$. These cells were stained with annexin V-FITC and PI, and then examined by flow cytometry. In each dot plot, the percentages of annexin V (-) and PI (-) (viable cells, bottom-left quadrant), annexin V (+) and PI (-) (cells in early stage apoptosis, bottomright quadrant), annexin $\mathrm{V}(+)$ and PI $(+)$ (cells in late stage apoptosis/ necrosis, top-right quadrant), and annexin V (-) and PI (+) (cells in necrosis, top-left quadrant) are described. (A), A-172; (B), U-251 MG cells.

with apoptosis and necrosis in the human glioma cell lines, A-172 and U-251 MG.

In order to clarify whether the inhibition of proliferation of A-172 and U-251 MG caused by phenoxazines such as Phx-1 and Phx-3 correlate with cell cycle arrest, we studied the effects of these phenoxazines on the progression of cell cycles (Fig. 4). It was found that Phx-1 and Phx-3 did not 


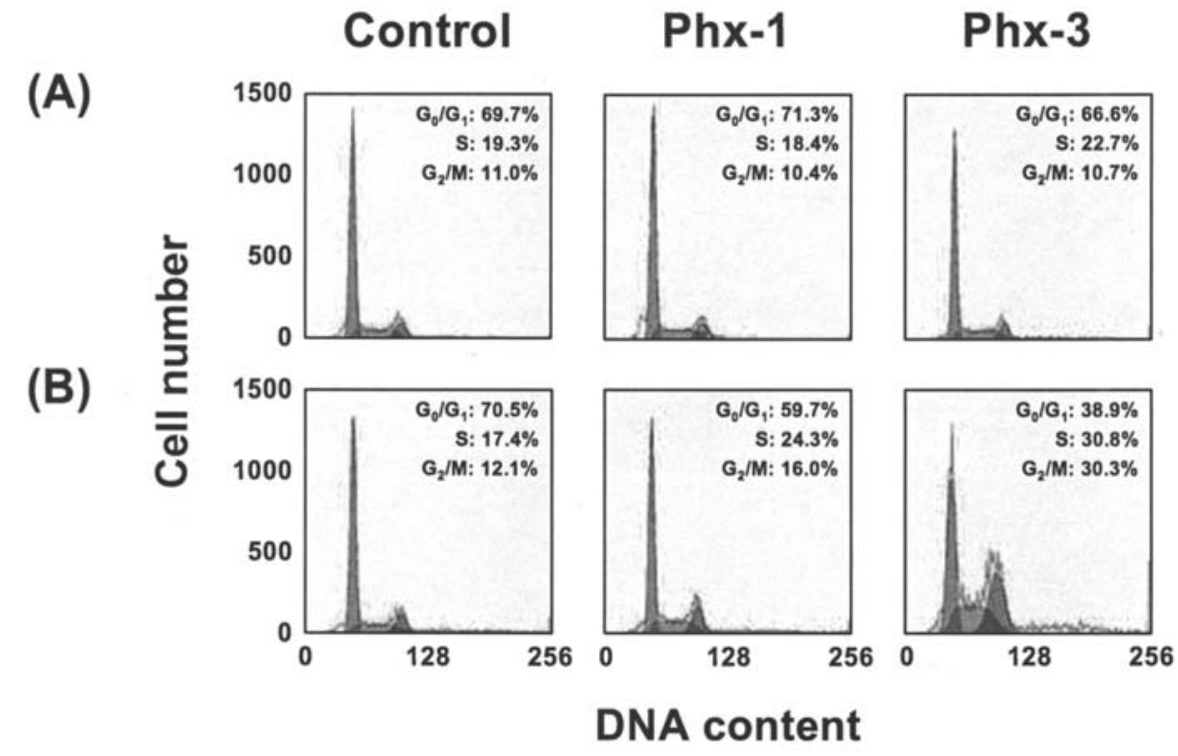

Figure 4. Effects of Phx-1 and Phx-3 on cell cycle in A-172 and U-251 MG. Cell cycle analysis was performed flow cytometrically using the CyStain DNA 2 step. A-172 cells were treated with or without $80 \mu \mathrm{M} \mathrm{Phx}-1$ or $30 \mu \mathrm{M} \mathrm{Phx}-3$, and U-251 MG cells were treated with or without $80 \mu \mathrm{M}$ Phx-1 or $10 \mu \mathrm{M}$ Phx-3 for $48 \mathrm{~h}$. The percentages (\%) of various cell cycle stages including $\mathrm{G}_{1} / \mathrm{G}_{0}, \mathrm{~S}$, and $\mathrm{G}_{2} / \mathrm{M}$ are depicted. (A), A-172; (B), U-251 MG cells.

(A)

Phx-1
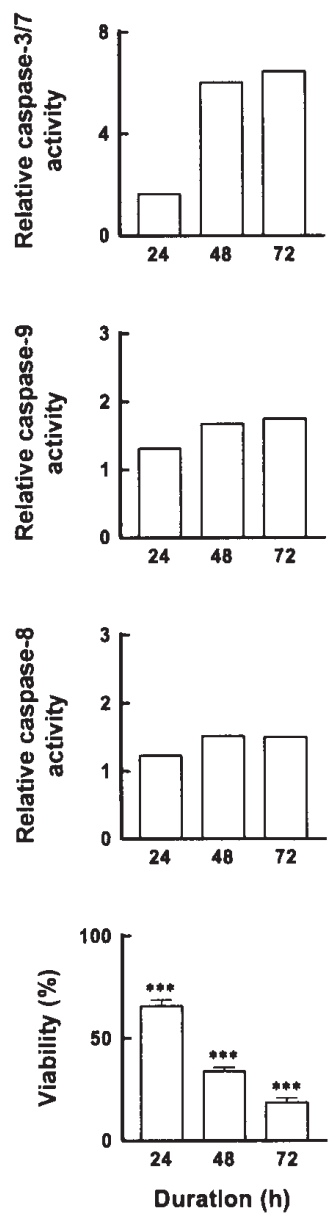

Phx-3
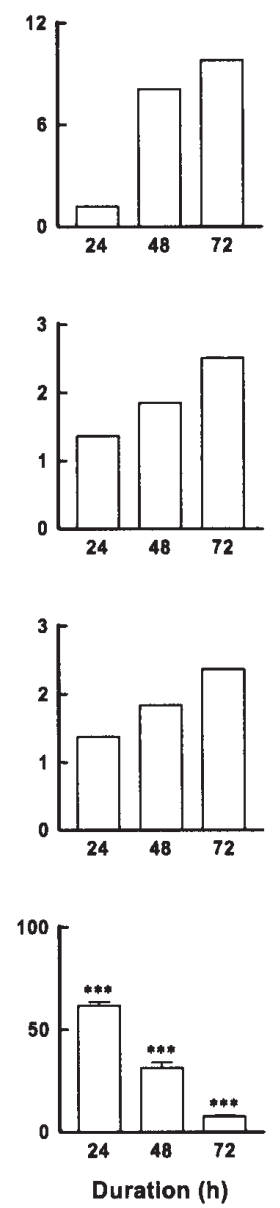

(B)

Phx-1

Phx-3
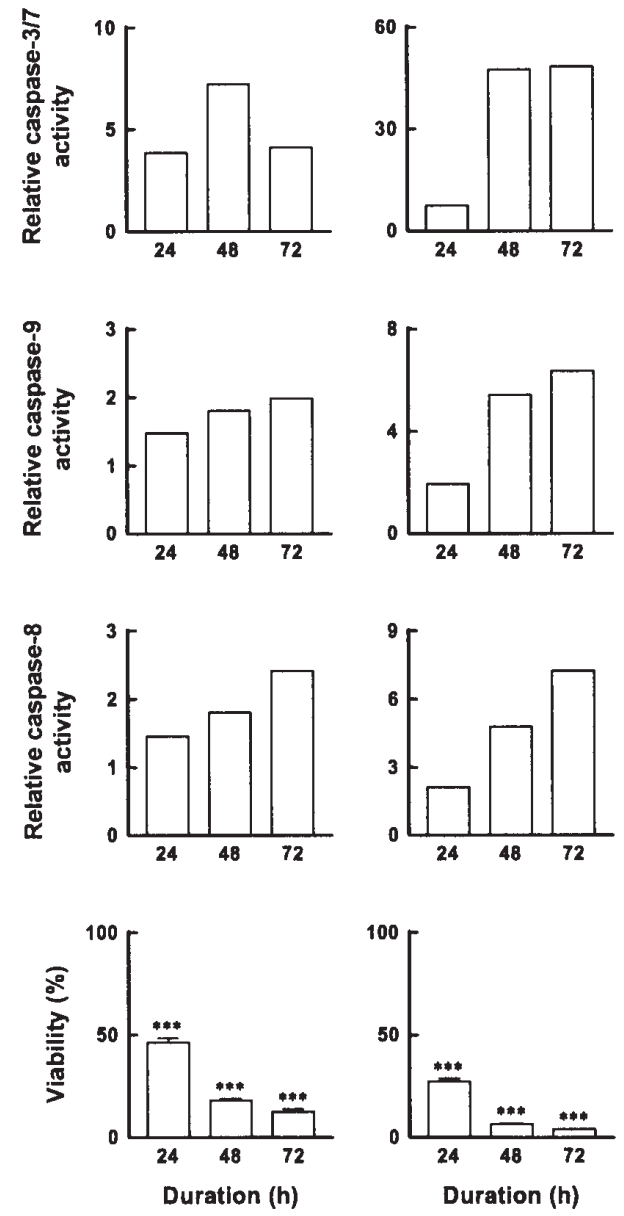

Figure 5. Changes in activities of caspase-3/7, -9 and -8 and viability in A-172 and U-251 MG cells. A-172 cells were treated with or without $80 \mu \mathrm{M}$ Phx- 1 or $30 \mu \mathrm{M}$ Phx-3, and U-251 MG cells were treated with or without $80 \mu \mathrm{M} \mathrm{Phx}-1$ or $10 \mu \mathrm{M}$ Phx-3 for 24, 48 and $72 \mathrm{~h}$. (A), A-172; (B), U-251 MG cells. ${ }^{* * * *} \mathrm{p}<0.001$ (vs. control cells). 
(A)
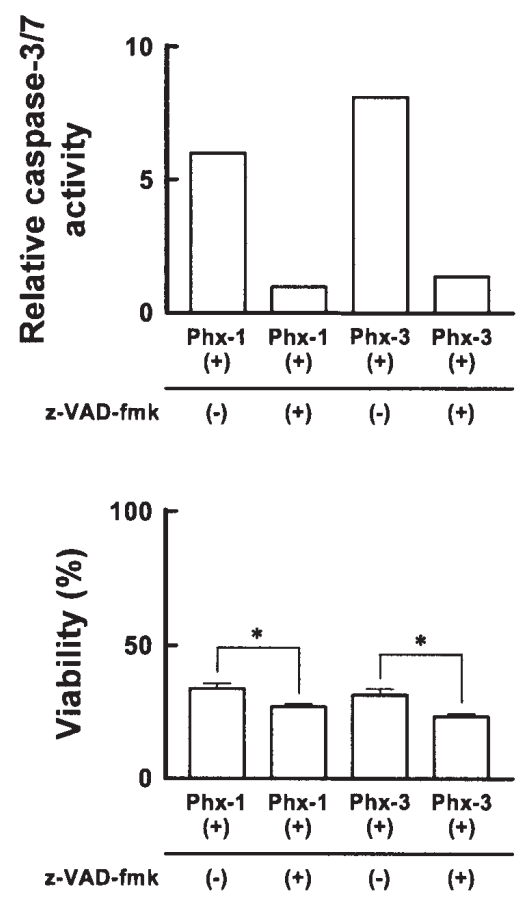

(B)
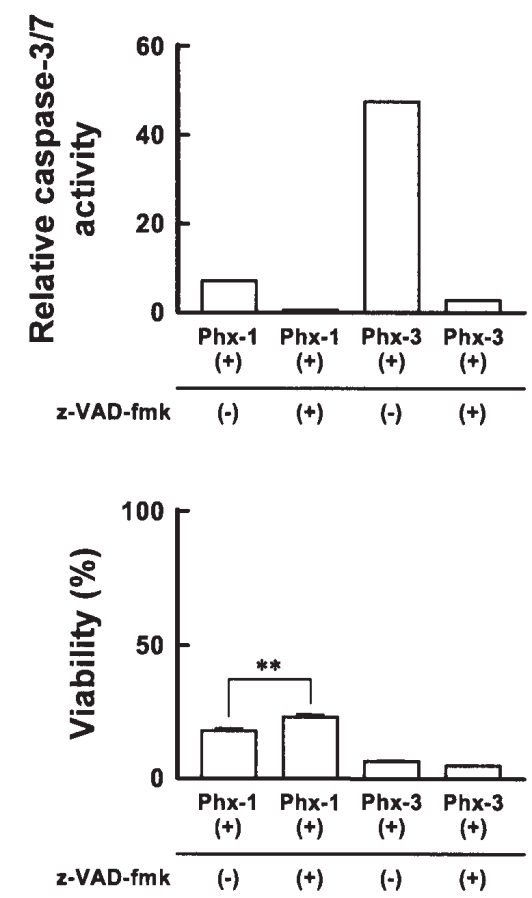

Figure 6. Effect of z-VAD-fmk on the activation of caspase-3/7 and the suppression of viability of A-172 cells and U-251 MG cells treated with Phx-1 or Phx-3. A-172 cells were treated with or without $80 \mu \mathrm{M} \mathrm{Phx}-1$ or $30 \mu \mathrm{M}$ Phx-3, and U-251 MG cells were treated with or without $80 \mu \mathrm{M}$ Phx-1 or $10 \mu \mathrm{M}$ Phx-3 for 48 h. (A), A-172; (B), U-251 MG cells. ${ }^{*} \mathrm{p}<0.05,{ }^{* *} \mathrm{p}<0.01$ (vs. cells treated without $\mathrm{z}-\mathrm{VAD}-\mathrm{fmk}$ ).

affect the progression of cell cycle in A-172 cells (Fig. 4A), whereas both these phenoxazines, particularly $\mathrm{Phx}-3$, strongly induced $\mathrm{S}$ and $\mathrm{G}_{2} / \mathrm{M}$ phase arrest in U-251 MG cells (Fig. 4B). This result suggests that antiproliferative and apoptotic effects of Phx-1 or Phx-3 were associated with $\mathrm{S}$ and $\mathrm{G}_{2} / \mathrm{M}$ arrest in U-251 MG cells, but not in A-172 cells.

Effects of Phx-1 and Phx-3 on the activities of caspase family proteases in A-172 and U-251 MG cells. To elucidate the involvement of the apoptotic signaling pathway in the apoptosis/necrosis of A-172 and U-251 MG cells, the activities of caspase-3/7, -9 and -8 were systematically examined in these cells treated with Phx-1 or Phx-3 for 24, 48 and $72 \mathrm{~h}$. As shown in Fig. 5A, the activities of caspase-3/7 in A-172 cells were markedly increased in a time-dependent manner by treatment with $80 \mu \mathrm{M} \mathrm{Phx}-1$ or $30 \mu \mathrm{M}$ Phx-3. After $48 \mathrm{~h}$, the activities of caspase-3/7 in A-172 cells treated with $80 \mu \mathrm{M}$ $\mathrm{Phx}-1$ and $30 \mu \mathrm{M} \mathrm{Phx}-3$ were 6.0 and 8.1 times higher, respectively (Fig. 5A), compared with those in the control cells treated with vehicle alone. On the other hand, the activities of caspase-3/7 in U-251 MG cells were also markedly increased by treatment with $\mathrm{Phx}-1$ or Phx-3 (Fig. 5B). Surprisingly, after $48 \mathrm{~h}$, the activity of caspase-3/7 in U-251 MG cells treated with $10 \mu \mathrm{M}$ Phx-3 was 47.4 times higher than those in the control cells treated with vehicle alone. In comparison with caspase-3/7, the increment of the activities of caspase- 9 and -8 in A-172 and U-251 MG cells caused by $\mathrm{Phx}-1$ or Phx-3 was moderate (Fig. 5). These results seemed to correlate with the antiproliferative and apoptotic effects of Phx-1 and Phx-3 against A-172 and U-251 MG cells as shown in Figs. 2 and 3.
Reversing effects of $z-V A D$-fmk on the antiproliferative and apoptotic effects of Phx-1 and Phx-3 in A-172 and U-251 MG cells. If the augmented activities of the caspase family proteases induced by $\mathrm{Phx}-1$ or Phx-3 were normalized in A-172 and U-251 MG cells, the inhibition of proliferation of these cells might recover to normal levels (100\%). In order to examine this hypothesis, we studied whether the antiproliferative and apoptotic effects of Phx-1 and Phx-3 in A-172 and U-251 MG cells were dependent on the elevation of caspase family activities, by using a pan-caspase inhibitor, z-VADfmk. As shown in Fig. 6A, the activation of caspase-3/7 caused by $\mathrm{Phx}-1$ or Phx-3 was completely cancelled by cotreatment with $100 \mu \mathrm{M}$ z-VAD-fmk in A-172 cells. However, Phx-1- and Phx-3-induced suppression of the proliferation of A-172 cells ( $40 \%$ of normal control in both cases with Phx-1 or Phx-3) was not reversed to normal levels (100\%) by the treatment with $100 \mu \mathrm{M}$ z-VAD-fmk. Similar results were obtained for U-251 MG cells co-treated with $100 \mu \mathrm{M} \mathrm{z}$-VADfmk (Fig. 6B). As shown in Fig. 7, Phx-1 and Phx-3-induced apoptosis/necrosis in A-172 and U-251 MG cells was not inhibited by co-treatment with z-VAD-fmk. These results strongly support the concept that the apoptosis/necrosis of A-172 and U-251 MG cells caused by Phx-1 or Phx-3 may be associated with a pathway independent of the activation of caspase family proteases.

\section{Discussion}

Apoptosis has been recognized as a highly regulated cellular response to various external signals, and can be triggered by 


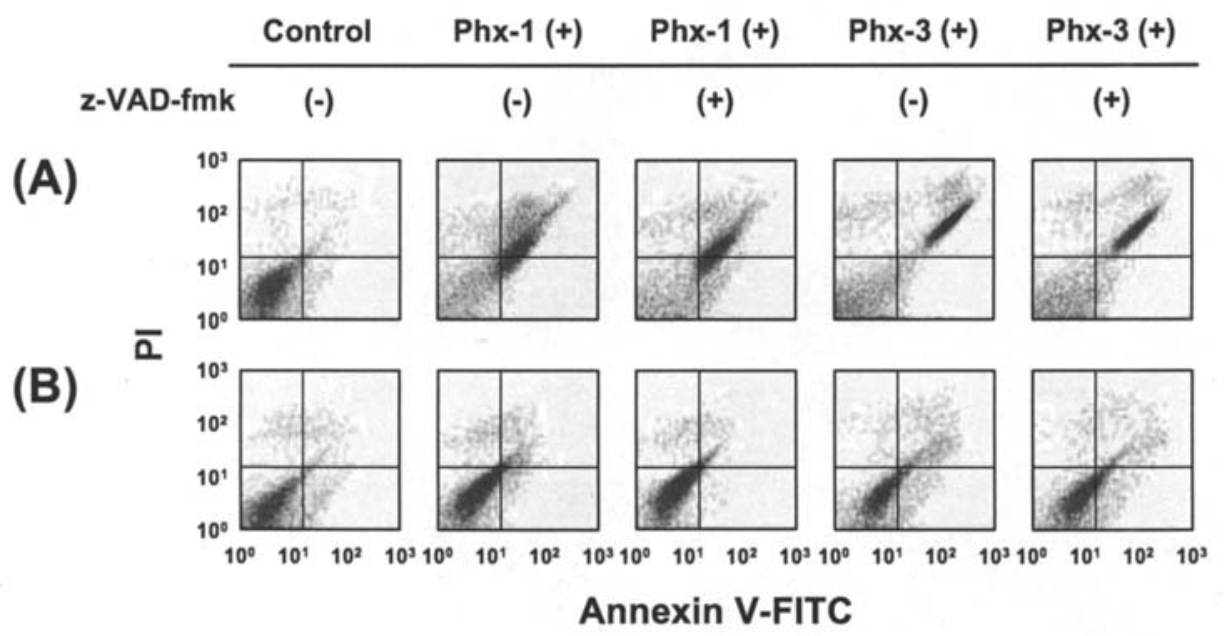

Figure 7. Effects of z-VAD-fmk on the apoptosis/necrosis of A-172 cells and U-251 MG cells induced by Phx-1 or Phx-3. The population of viable cells and the cells in early stage apoptosis, late stage apoptosis/necrosis, and necrosis among human glioblastoma cell lines, A-172 cells and U-251 MG cells was detected by a flow cytometric assay. These cells were grown in the presence or absence of Phx-1 or Phx-3 (the concentrations are described in the legend to Fig. 5) with or without $100 \mu \mathrm{M}$ z-VAD-fmk, for $48 \mathrm{~h}$. In each dot plot, the percentages of annexin V (-) and PI (-) (viable cells, bottom-left quadrant), annexin V (+) and PI (-) (cells in early stage apoptosis, bottom-right quadrant), annexin V (+) and PI (+) (cells in late stage apoptosis/necrosis, top-right quadrant), and annexin V (-) and PI (+) (cells in necrosis, top-left quadrant) are described. (A), A-172; (B), U-251 MG cells.

the extrinsic pathways activated through cell surface death receptors and the intrinsic pathway involving changes in permeability of the mitochondrial membrane and release of apoptogenic substances such as cytochrome c leading to the activation of caspase-3, a major final executing caspase of apoptosis $(6,17,18)$. In the present study, it was demonstrated that Phx-1 and Phx-3 decreased the viability of human glioblastoma cell lines, A-172 and U-251 MG in a dose- and timedependent manner (Fig. 2) and caused significant cellular death including the late stage apoptosis/necrosis (Fig. 3). These results suggest that $\mathrm{Phx}-1$ and $\mathrm{Phx}-3$ may induce not only the activation of apoptotic signaling pathway but also the early plasma membrane damage in the human glioblastoma cell lines. It has been generally recognized that the activation of caspase family proteases, especially of caspase-3, as an executing enzyme, is crucial to the induction of cellular apoptosis $(3,4)$. We observed that caspase-3/7 were extensively activated in both A-172 and U-251 MG cells treated with Phx-1 or Phx-3 for more than $48 \mathrm{~h}$ (Fig. 5), in accordance with the suppression of cellular viability and the induction of apoptosis (Figs. 2 and 3). Judging from these results alone, the apoptosis may be closely associated with the activation of caspase-3/7, in the cells treated with these phenoxazines.

However, our present results shown in Figs. 6 and 7 seem to contradict this view, because the Phx-1 or Phx-3 suppression of the proliferation of A-172 and U-251 MG cells was not reversed to normal levels by the addition of $\mathrm{z}-\mathrm{VAD}-\mathrm{fmk}$, a pan-caspase inhibitor, in spite of the cancellation of the activated caspases. Therefore, the suppression of proliferation and the induction of apoptosis in A-172 and U-251 MG cells may be independent of the activation of caspase family proteases. According to recent reports $(2,5,7)$, the caspase independent pathway associated with AIF and BNIP3 is involved in the induction of apoptosis. Park et al (9) indicated that allicin, a major component of garlic, cause apoptosis in gastric carcinoma cells through a caspase-independent cell death pathway, accompanying the release of AIF from mitochondria instead of the activation of caspase-3. Furthermore, Ribas et al (19) reported that 8-bromoindirubin-3'-oxime induced caspase-independent cell death in neuroblastoma SH-SY5Y cells, without the activation of caspase-3. Therefore, our present results seem consistent with the views that the caspase independent pathway associated with AIF and BNIP3 may be involved in the apoptosis of these cells.

It has been suggested that the suppression of proliferation and apoptotic cellular death of cancer cells caused by anticancer drugs are linked to cell cycle arrest (20). The results in Fig. 4 show distinct modes of the cell cycle arrest in A172 and U-251 MG cells treated with $\mathrm{Phx}-1$ or $\mathrm{Phx}-3$, i.e., the progression of cell cycle was not disturbed in A-172 cells treated with $\mathrm{Phx}-1$ or Phx-3, while the cell cycle was arrested at $\mathrm{S}$ and $\mathrm{G}_{2} / \mathrm{M}$ in U-251 MG cells treated with Phx-1 or Phx-3. Phx-1 has been shown to induce cell cycle arrest at $G_{1}$ or $S$ and $G_{2} / M$ in the human leukemia cell lines, Burkitt lymphoblastoma cell lines and a human malignant melanoma cell line (12-14). However, we recently observed that cell cycle arrest did not occur in a neuroblastoma cell line, NB-1 cells, treated with $\mathrm{Phx}-1$ or $\mathrm{Phx}-3$, while the suppression of proliferation and apoptosis occurred under the same conditions (data not shown). These results suggest that the suppression of proliferation and apoptotic cellular death of cancer cells caused by anticancer drugs are not necessarily linked to the cell cycle arrest.

The strong activation of caspase-3/7 and moderate activation of caspases- 8 and -9 in A-172 cells and U-251 MG cells treated with Phx-1 or Phx-3 (Fig. 5) may be attributed to the consequence of mitochondrial disturbance in these cancer cells, resulting in the release of cytochrome c, though the meaning of the activation of these caspases by $\mathrm{Phx}-1$ and Phx-3 is still obscure. Enoki et al reported that the antigeninduced phosphorylation of Akt was inhibited in mast cells treated with Phx-1 (24). Since the phosphorylation of Akt 
(protein kinase B), has the anti-apoptotic capacity of inactivating pro-apoptotic proteins such as Bad (21), Forkhead transcription factors (22), and caspase-9 (23), it is conceivable that Phx-1 and Phx-3 may indirectly activate the mitochondriamediated or intrinsic pathway, by inhibiting the phosphorylation of Akt. This view is consistent with the results of Hara et al (25) who showed that when Jurkat cells, a human T cell leukemic cell line, were treated with $\mathrm{Phx}-1$, mitochondrial depolarization, and inhibition of serum-induced Akt phosphorylation were induced, which may lead to the activation of caspase family proteases on the one hand, and to the apoptotic cellular death independent of caspases, on the other.

Among phenoxazines, an essential component of actinomycin D, which has anticancer activity but with accompanying adverse reaction (26), $\mathrm{Phx}-1$ and $\mathrm{Phx}-3$ have been indicated to exert various biological effects such as anticancer activity (12-16,27), immunosuppressive activity $(24,28)$, antimicrobial activity $(11,29,30)$ and vasodilating activity (31). With regard to human glioblastoma cell lines, A-172 and $\mathrm{U}-251 \mathrm{MG}$, the antiproliferative effects of $\mathrm{Phx}-3$ were stronger than those of Phx-1, which may be related to the difference in chemical structure between these phenoxazines, i.e., the presence or absence of the methyl group in the tricyclic chromophore as shown in Fig. 1 may affect the action mode of these phenoxazines, though details of the mechanism are unclear.

Gliomas are the most common primary central nervous system tumors in adults (32-35). The vast majority of these tumors are derived from astrocytes and oligodendrocytes of glial cell subtypes $(33,35)$. The high grade III and IV astrocytomas are called anaplastic astrocytoma and glioblastoma multiforme, respectively, according to the definition of The World Health Organization (WHO) $(34,35)$, and are extremely difficult to treat. Thus, there is an urgent need to develop drugs exerting anticancer effects on these malignant brain tumors. In addition, the development of the anticancer drugs that can cross the blood-brain barrier is necessary. In light of the fact that phenoxazine derivatives and phenothiazines in use are shown to pass the blood-brain barrier and show various pharmacological effects without any reported adverse effects (36), Phx-1 and Phx-3 may hold promise as agents to treat malignant brain tumors including glioma, which is extremely unresponsive to presently available chemotherapeutic drugs.

\section{Acknowledgements}

We thank Professor J. Patrick Barron (International Medical Communication Center of Tokyo Medical University) for his review of the English manuscript. The present research was supported in part by funds from the High-Tech Research Project for Private Universities, and a matching fund subsidy from the Ministry of Education, Culture, Sports and Technology, Japan (2003-2007) and by funds from the Ito Foundation.

\section{References}

1. Barry MA, Behnke CA and Eastman A: Activation of programmed cell death (apoptosis) by cisplatin, other anticancer drugs, toxins and hyperthermia. Biochem Pharmacol 40: 2353-2362, 1990.
2. Sen S and D'Incarci M: Apoptosis: biochemical events and relevance to cancer thermotherapy. Fed Eur Biochem Socie 307: 122-127, 1992.

3. Thornberry NA and Lazebnik Y: Caspases: enemies within. Science 298: 1312-1316, 1998.

4. Green D and Kroemer G: The central executioners of apoptosis: caspases or mitochondria? Trends Cell Biol 8: 267-271, 1998.

5. Lorenzo HK, Susin SA, Penninger J and Kroemer G: Apoptosis inducing factor (AIF): a phylogenetically old, caspaseindependent effector of cell death. Cell Death Differ 6: 516-524, 1999.

6. Hail N Jr, Carter BZ, Konopleva M and Andreeff M: Apoptosis effector mechanisms: a requiem performed in different keys. Apoptosis 11: 889-904, 2006.

7. Vande Velde C, Cizeu J, Dubik D, Alimonti J, Brown T, Israels S, Hakem R and Greenberg AH: BNIP3 and genetic control of necrosis-like cell death through the mitochondrial permeability transition pore. Mol Cell Biol 20: 5454-5468, 2000.

8. Hong SJ, Dawson TM and Dawson VL: Nuclear and mitochondrial conversation in cell death: PARP-1 and AIF signaling. Trends Pharmacol Sci 25: 259-264, 2004.

9. Park SY, Cho SJ, Kwon HC, Lee KR, Rhee DK and Pyo S: Caspase-independent cell death by allicin in human epithelial carcinoma cells: involvement of PKA. Cancer Lett 224: 123-132, 2005.

10. Tomoda A, Arai S, Ishida R, Shimamoto T and Ohyashiki K: An improved method for the rapid preparation of a novel antitumor agent. Biorg Med Chem Lett 11: 1057-1058, 2002.

11. Shimizu S, Suzuki M, Tomoda A, Arai S, Taguchi H, Hanawa T and Kamiya S: Phenoxazine compounds produced by the reactions with bovine hemoglobin show antimicrobial activity against non-tuberculosis mycobacteria. Tohoku J Exp Med 203: 47-52, 2004

12. Shimamoto T, Tomoda A, Ishida R and Ohyashiki K: Antitumor effects of novel phenoxazine derivative on human leukemia cell lines in vitro and in vivo. Clin Cancer Res 7: 704-708, 2001 .

13. Abe A, Yamane M and Tomoda A: Prevention of growth of human lung carcinoma cells and induction of apoptosis by a novel phenoxazine, 2 -amino-4,4 $\alpha$-dihydro- $4 \alpha, 7$-dimethyl-3Hphenoxazine-3-one. Anticancer Drugs 12: 377-381, 2001.

14. Shimizu S, Suzuki M, Miyazawa K, Yokoyama T, Ohyashiki K, Miyazaki K, Abe A and Tomoda A: Differentiation and apoptosis in human malignant melanoma G-361 cells induced by 2-aminophenoxazine-3-one. Oncol Rep 14: 41-46, 2005.

15. Koshibu-Koizumi J, Akazawa M, Iwamoto T, Takasaki M, Mizuno F, Kobayashi R, Abe A, Tomoda T, Hamatake M and Ishida R: Antitumor activity of a phenoxazine compound, 2amino-4,4 $\alpha$-dihydro-4 $\alpha, 7$-dimethyl-3H-phenoxazine-3-one against human $\mathrm{B}$ cell and $\mathrm{T}$ cell lymphoblastoid cell lines: induction of mixed types of cell death, apoptosis and necrosis. J Cancer Res Clin Oncol 128: 363-368, 2002.

16. Kato S, Shirato K, Imaizumi K, Toyoda H, Mizuguchi J, Odawara M, Che XF, Akiyama S, Abe A and Tomoda A: Anticancer effects of phenoxazine derivatives combined with tumor necrosis factor-related apoptosis-inducing ligand (TRAIL) on pancreatic cancer cell lines, KLM-1 and MIA-PaCa-2. Oncol Rep 15: 843-848, 2006.

17. Green DR and Reed JC: Mitochondria and apoptosis. Science 281: 1309-1312, 1998 .

18. Hengartner MO: The biochemistry of apoptosis. Nature 407: 770-776, 2000.

19. Ribas J, Bettayeb K, Ferandin Y, Knockaert M, Garrofe-Ochoa X, Totzke F, Schachtele C, Mester J, Polychronopoulos P, Magiatis P, Skaltsounis AL, Boix J and Meijer L: 7-Bromoindirubin-3'oxime induces caspase-independent cell death. Oncogene 25: 6304-6318, 2006.

20. Tobey RA: Different drugs arrest cells at a number of distinct stages in G2. Nature 254: 245-247, 1975.

21. Del Peso L, Gonzalez-Garcia M, Page C, Herrera R and Nunez G: Interleukin-3-induced phosphorylation of BAD through the protein kinase Akt. Science 278: 687-689, 1997.

22. Brunet A, Bonni A, Zigmond MJ, Lin MZ, Juo P, Hu LS, Anderson MJ, Arden KC, Blenis J and Greenberg ME: Akt promotes cell survival by phosphorylating and inhibiting a Forkhead transcription factor. Cell 96: 857-868, 1999.

23. Cardone MH, Roy N, Stennicke HR, Salvesen GS, Franke TF, Stanbridge E, Frisch S and Reed JC: Regulation of cell death protease caspase-9 by phosphorylation. Science 282: 1318-1321, 1998. 
24. Enoki E, Sada K, Qu X, Kyo S, Shahjahan Miah SM, Hatani T, Tomoda A and Yamamura Y: The phenoxazine derivative Phx-1 suppresses IgE-mediated degranulation in rat basophilic leukemia RBL 2H3 cells. J Pharmacol Sci 94: 329-333, 2004.

25. Hara K, Okamoto M, Aki T, Yagita H, Tanaka H, Mizukami Y, Nakamura H, Tomoda A, Hamasaki N and Kang D: Synergistic enhancement of TRAIL- and TNF $\alpha$-induced cell death by a phenoxazine derivative. Mol Cancer Ther 4: 1121-1127, 2005.

26. Hollstein U: Actinomycin. Chemistry and mechanism of action. Chem Rev 74: 625-652, 1974.

27. Mori H, Honda K, Ishida R, Nohira T and Tomoda A: Antitumor activity of 2 -amino- $4,4 \alpha$-dihydro- $4 \alpha, 7$-dimethyl- $3 \mathrm{H}$ phenoxazine-3-one against Meth A tumor transplanted into BALB/c mice. Anticancer Drugs 11: 653-657, 2000.

28. Gao S, Takano T, Sada K, Tomoda A and Yamamura H: A novel phenoxazine derivative suppresses surface $\operatorname{IgM}$ expression in DT40B cell line. Br J Pharmacol 137: 749-755, 2002.

29. Iwata A, Yamaguchi T, Sato K, Yoshitake N and Tomoda A: Suppression of proliferation of poliovirus and porcine parvovirus by novel phenoxazine, 2 -amino- $4,4 \alpha$-dihydro- $4 \alpha, 7$-dimethyl$3 \mathrm{H}$-phenoxazine-3-one and 3-amino-1,4 $\alpha$-dihydro-4 $\alpha, 8$-dimethyl2H-phenoxazine-2-one. Biol Pharm Bull 28: 905-907, 2005.

30. Uruma T, Yamaguchi H, Fukuda M, Kawakami H, Goto H, Kishimoto T, Yamamoto Y, Tomoda A and Kamiya S: Clamydia pneumoniae growth inhibition in human monocytic THP-1 cells and human epithelial HEp-2 cells by a novel phenoxazine derivative. J Med Microbiol 54: 1143-1149, 2005.
31. Musha S, Watanabe M, Ishida Y, Kato S, Konishi M and Tomoda A: A phenoxazine compound, 2-amino-4,4 $\alpha$-dihydro$4 \alpha, 7$-dimethyl-3H-phenoxazine-3-one reverses the phenylephrine or high-K+ induced contraction of smooth muscles in rat aorta and Guinea pig tenia cecum. Biol Pharm Bull 28: 1521-1523, 2005.

32. Lefranc F, Brotchi J and Kiss R: Possible future issues in the treatment of glioblastomas: special emphasis on cell migration and the resistance of migrating glioblastoma cells to apoptosis. $\mathbf{J}$ Clin Oncol 23: 2411-2422, 2005.

33. Lassman AB: Molecular biology of gliomas. Curr Neural Neurosci Rep 4: 228-233, 2004.

34. Dai C, Lyustikman Y, Shih A, Hu X, Fuller GN, Rosenblum M and Holland EC: The characteristics of astrocytoma and oligodendrogliomas are caused by two distinct and interchangeable signaling formats. Neoplasia 7: 397-406, 2005.

35. Butowski NA, Sneed PK and Chang SM: Diagnosis and treatment of recurrent high-grade astrocytoma. J Clin Oncol 24: 1273-1280, 2006

36. Azuine MA, Tokuda H, Takayasu J, Enjyo F, Mukainaka T, Konoshima T, Nishino $\mathrm{H}$ and Kapadia GF: Cancer chemopreventive effect of phenothiazines and related tri-heterocyclic analogues in the 12-O-tetradecanoylphorbol-13-acetate promoted Epstein-Barr virus early antigen activation and the mouse skin two-stage carcinogenesis models. Pharmacol Res 49: 161-169, 2004. 